\title{
CuZnSOD gene expression and its relationship with anti-oxidative capacity and pork quality
}

\author{
Jinfang Du, Yongqing Zeng", Hui Wang\#, Yuan Qian, Hua Li, Qimei Chen, Wei Chen and \\ Jingxiang Cui \\ College of Animal Science and Technology, Shandong Agricultural University, 271018, Taian, P. R. China
}

\begin{abstract}
The antioxidant enzyme, copper zinc superoxide dismutase (CuZnSOD) plays an important role in protecting tissues from damage by reactive oxygen species (ROS) reactions. The objective of this investigation was to determine the CuZnSOD mRNA level as an indicator of CuZnSOD activity and the effect it has on meat quality in three important pig breeds in China, the Laiwu Black (LW), Lulai Black (LL) and Large Yorkshire (LY). Thirty six castrated boars (114 kg; LW, $\mathrm{n}=12 ; \mathrm{LL}, \mathrm{n}=12$ and LY, $\mathrm{n}=12$ ) were used in this study. Samples were taken from the longissimus dorsi muscle, backfat and liver. Results showed that there was a significant breed $\times$ tissue interaction; and the maximum mRNA level of the CuZnSOD gene was recorded in the LW and the minimum in the LY. The proportion of gene expression was positively correlated with the anti-oxidative capacity in muscle. The expression of the CuZnSOD gene was positively correlated with meat colour and tenderness; and negatively correlated with marbling score, drip loss, cooking loss and intramuscular fat. The higher the level of CuZnSOD mRNA expression, the better was the quality of the pork. This implies that the difference in CuZnSOD mRNA expression in breeds was involved in the mechanisms of meat quality that related to superoxide dismutase (SOD) activity and anti-oxidant capacity of the muscle.
\end{abstract}

Keywords: Anti-oxidative activity, copper zinc superoxide dismutase, meat quality, swine

${ }^{\#}$ Corresponding authors. E-mail: yqzeng@sdau.edu.cn; E-mail: wanghui2328@sdau.edu.cn

\section{Introduction}

Oxidation rate of post mortem muscle depends on the anti-oxidative capacity in the animal; superoxide dismutase (SOD, EC 1.15.1.1) can prevent oxidation reactions to improve meat quality and extend the shelf life of meat products. It is well documented that reactive oxygen species (ROS), such as superoxide anion and hydrogen peroxide, organic peroxide and hydroxyl radical are products of normal metabolic activities and are produced in response to various stimuli (Halliwell, 1991). Under normal conditions there is a balance between the production of ROS and their destruction. However, overproduction of ROS can attack biological macromolecules such as lipids, protein and DNA, induce oxidation and cause membrane damage, enzyme inactivation and DNA damage, and can even contribute to the development of various diseases (Miao et al., 2009). In order to cope with an excess of free radicals produced through oxidative stress, mammals have developed sophisticated mechanisms. The main antioxidant enzymes include SOD, glutathione peroxidase (GPX, EC 1.11.1.9) and catalase (CAT, EC 1.11.1.6) which act in a cooperative or synergistic way to ensure global cell protection (Yu et al., 2007; Day, 2009). Numerous studies have shown that GPX expression in mammals is regulated by many factors (Frank \& Sosenko, 1987; Yuan et al., 1996). However, SOD has not been studied well in this respect.

Reactive oxygen species react with the double bonds of polyunsaturated fatty acids (PUFAs) to yield lipid hydroperoxides. One of the major secondary oxidation products of peroxidized PUFAs is malondialdehyde (MDA) (Mateos et al., 2005). SOD plays an essential role in protecting organism against damage by the superoxide anion radical, and is the most important enzyme to efficiently catalyze the dismutation of superoxide anions into $\mathrm{O}_{2}$ and $\mathrm{H}_{2} \mathrm{O}_{2}$, which are detoxified either to $\mathrm{H}_{2} \mathrm{O}$ and $\mathrm{O}_{2}$ by CAT or to $\mathrm{H}_{2} \mathrm{O}$ by GPX (Michiels et al., 1994). Therefore, the activity of SOD and the content of MDA could represent anti-oxidative ability in pork.

At present three distinct isoforms of SOD have been identified in mammals (Covarrubias et al., 2008). They are copper zinc superoxide dismutase (CuZnSOD, SOD1), manganese superoxide dismutase (MnSOD, 
SOD2) (Takada et al., 2009) and extracellular superoxide dismutase (Ec-SOD, SOD3). CuZnSOD is the enzyme characterized with a copper and zinc-containing homodimer. MnSOD exists as a tetramer and is initially synthesized containing a leader peptide, which targets this manganese-containing enzyme exclusively to the mitochondrial spaces. ECSOD, the most recently characterized SOD, exists as a copper and zinc-containing tetramer, and is synthesized with a signal peptide that directs this enzyme exclusively to extracellular spaces. CuZnSOD is found almost exclusively in intracellular cytoplasmic spaces, and comprises $90 \%$ of total SOD (Noor et al., 2002). Therefore, the investigation of CuZnSOD expression levels becomes very important.

Pork quality is an important economic characteristic, and has become a primary focus for producers, researchers and consumers in recent years. It has been widely acknowledged that there are significant differences in pork quality between pig breeds. The Laiwu Black (LW) is mainly raised in the Shandong Province of China. Lulai Black (LL) with good meat quality is a breed based on LW with introgression of the Large Yorkshire (LY). Compared with LY, the meat of the LW has a higher intramuscular fat (IMF) content and a better flavour (Hu et al., 2008; Lu et al., 2008). Differences between these breeds are, in part, the results of factors such as genetics. However, little is known about the molecular aspects affecting these traits.

Transcriptomics is a technology that may help to identify molecular markers of meat quality. In a previous study we found that the activity of antioxidant enzyme and MDA content influenced water-holding capacity (WHC), shear force and IMF. It is currently not known whether transcriptomics corresponding to the CuZnSOD gene is also correlated with meat quality, or whether the gene is an indirect marker of meat quality.

\section{Material and Methods}

The animal care and usage protocol was reviewed and approved by the Shandong Agricultural University Animal Nutrition Research Institute. Three genetically different pig breeds, the Laiwu Black (LW), Lulai Black (LL) and Large Yorkshire (LY) were used in this study. LW is a Chinese native pig breed. This breed has a lower growth performance than most commercial European pigs such as the LY. LL was developed from the crossing of the LW and LY at a $50: 50$ ratio. Twelve boars from each breed were castrated at 15 days of age. The pigs were fed as a group at the Laiwu breeding farm (Laiwu, China), and were slaughtered when LY, LL and LW reached live weights of $c a .114( \pm 2) \mathrm{kg}$ at respectively 6,9 and 12 months of age.

Samples of the longissimus muscle, backfat and liver were collected from the carcasses for mRNA expression analysis, and were preserved in liquid nitrogen. The whole longissimus muscle from the other half of the carcass was taken to determine SOD activity and MDA concentration, as well as meat quality.

The longissimus lumbar dorsi was taken for determination of SOD activity and MDA concentration. After 1, 2, 3 and 5 days of storage at $4{ }^{\circ} \mathrm{C}, \mathrm{SOD}_{1 \mathrm{~d}}, \mathrm{SOD}_{2 \mathrm{~d}}, \mathrm{SOD}_{3 \mathrm{~d}}, \mathrm{SOD}_{5 \mathrm{~d}}$ activities and MDA $1 \mathrm{~d}, \mathrm{MDA}_{2 \mathrm{~d}}$, $\mathrm{MDA}_{3 \mathrm{~d}}, \mathrm{MDA}_{5 \mathrm{~d}}$ concentrations, respectively, were measured, using a SOD Detection Kit and an MDA Detection Kit (Nanjing, China).

Meat colour and marbling score of the longissimus thoracis dorsi were measured by a trained, twoperson panel (Lonergan et al., 2002; Ryan et al., 2010). Colour score measurements were taken using the standardized colour scale (scale, $1=$ light-coloured pork to $6=$ dark-coloured pork, scored to the nearest 0.5 ). Marbling score was obtained using a continuous scale of photographs (on 1 to 5 scales) of pork chops containing low to high levels of IMF. The scores from the two-person panel were averaged to assign the final marbling score.

Longissimus thoracis muscle in the region of the last rib was taken for drip loss, cooking losses, shear force and IMF evaluation. In order to measure drip loss (\%), meat samples were weighed and then suspended in an inflated polyethylene bag without any contact with the bag. After a $24 \mathrm{~h}$ storage period at $4{ }^{\circ} \mathrm{C}$, the samples were dried gently with paper towels and reweighed (Honikel, 1998). Cooking loss was determined using the method described by Honikel (1998). Meat samples were cooked to a final core temperature of $71^{\circ} \mathrm{C}$, and cooking losses were estimated by weighing before and after cooking. After the measurement of cooking loss, cooked samples were used to determine shear force values using a Warner-Bratzler shearing device. IMF was chemically quantified following ISO, 1443-1973. The method used was direct soxhlet extraction of fat by the solvent, ether. 
Total RNA was isolated from muscle, backfat and liver samples using the Trizol Reagent Kit (Bioteke, China) according to the manufacturer's instructions. The extracted RNA was dissolved in DEPC-treated water and the concentration, purity and integrity were assessed using an Eppendorf Biophotometer (Germany) at 260/280 nm (OD260/OD280 = $1.8-2.0)$, and by electrophoresis in a 1\% agarose gel to verify its integrity. Total RNA ( $5 \mu \mathrm{g}$ ) was treated with $3 \mathrm{U}$ of DNase I (Takara, Japan) to remove contaminating genomic DNA. Total RNA ( $2 \mu \mathrm{g}$ ) was used as a template for cDNA synthesis using oligo (dT) primer. The RNA sample, oligo (dT) and sterile $\mathrm{H}_{2} \mathrm{O}$ (final volume, $11 \mu \mathrm{L}$ ) were mixed in a $0.5 \mathrm{~mL}$ microcentrifugal tube and incubated at $70{ }^{\circ} \mathrm{C}$ for $5 \mathrm{~min}$, and then cooled on ice for $1 \mathrm{~min}$. The rest of the reagents except reverse transcriptase (Bioteke, China) was then added into the reaction tube with a final volume of $19 \mu \mathrm{L}$ and incubated at $37^{\circ} \mathrm{C}$ for $5 \mathrm{~min}$. M-MLV RT (200U) (Bioteke, China) was then added into the reaction tube with a final volume of $20 \mu \mathrm{L}$, and the reaction was incubated at $42{ }^{\circ} \mathrm{C}$ for $60 \mathrm{~min}$, and finally was terminated by heating at $70^{\circ} \mathrm{C}$ for $10 \mathrm{~min}$. Reverse transcriptase (RT) production was stored at $-20^{\circ} \mathrm{C}$.

According to the published mRNA sequences of swine CuZnSOD (AF396674) at GenBank, the oligonucleotide primers set for the gene were designed using Primer Premier 5.0 software and described in detail in Table 1. The primers of glyceraldehydes-3-phosphate dehydrogenase (GAPDH) gene were the primers reported by Erkens et al. (2006).

Table 1 Information on the primers of the CuZnSOD and GAPDH genes used for qPCR

\begin{tabular}{llcc}
\hline Genes & Primer sequences $\left(5^{\prime}-3^{\prime}\right)$ & Product length $(\mathrm{bp})$ & Anneal Temp $\left({ }^{\circ} \mathrm{C}\right)$ \\
\hline \multirow{2}{*}{ CuZnSOD } & $\begin{array}{l}\text { Forward: GGTCCTCACTTCAATCCTG } \\
\text { Reverse: CTTCATTTCCACCTCTGC }\end{array}$ & 217 & 58 \\
GAPDH & $\begin{array}{l}\text { Forward: ACTCACTCTTCTACCTTTGATGCT } \\
\text { Reverse: TGTTGCTGTAGCCAAATCA }\end{array}$ & 100 & 58 \\
\hline
\end{tabular}

All qPCR assays were carried out on a Stratagene Mx3000P device. The continuously expressed gene, GAPDH, was used, and served as an endogenous reference for determination of targeted mRNA profiles (Robert et al., 2005; Malathi et al., 2008). The $2^{-\Delta \Delta \mathrm{Ct}}(\Delta \Delta \mathrm{Ct}=\Delta \mathrm{Ct}$ of the target gene - $\Delta \mathrm{Ct}$ of the housekeeping gene) method was used to analyse the relative quantitative data (Livak et al., 2001; Yuan et al., 2008). QPCR amplifications were performed in a $20 \mu \mathrm{L}$ reaction volume consisting of $100 \mathrm{nM}$ forward primer and reverse primer, $2 \mu \mathrm{L}$ of cDNA, $10 \mu \mathrm{L}$ SYBR Green Realtime PCR Master Mix and $2 \mu \mathrm{L}$ of Plus Solution (Toyobo, Japan). The following amplification conditions were used: one cycle of $30 \mathrm{~s}$ at $95{ }^{\circ} \mathrm{C}$, followed by $35 \mathrm{PCR}$ cycles of $5 \mathrm{~s}$ at $95{ }^{\circ} \mathrm{C}, 10 \mathrm{~s}$ at $58^{\circ} \mathrm{C}$ and a final extension for $15 \mathrm{~s}$ at $72{ }^{\circ} \mathrm{C}$.

Data were statistically analyzed using SAS Software (SAS, 1999). Different gene expression levels of the three tissues and the three breeds were analyzed by Bivariate Correlations with repeated measures. Correlation analysis among CuZnSOD mRNA expression levels, anti-oxidative activity of muscles and meat quality were calculated using the PROC CORR procedure of SAS 8.1. The results are presented as means \pm standard error of the mean (s.e.m.). Significant and extreme differences were set at $\mathrm{P}<0.05$ and $\mathrm{P}<0.01$, respectively.

\section{Results}

The expression of CuZnSOD gene was determined in the three selected tissues, and indicated a breed $\times$ tissue interaction $(\mathrm{P}=0.005)$. CuZnSOD mRNA expression WAs not only influenced by different tissues, but also by different breeds. In all three pig breeds, CuZnSOD mRNA expression levels were the highest in the backfat, followed by the liver and the lowest in muscle $(\mathrm{P}<0.05)$. The CuZnSOD mRNA expression levels in backfat, muscle and liver were significantly different in the three breeds, with CuZnSOD mRNA expression level being the highest in the LW, followed by that in the LL, and the lowest in the LY (Figure 1). 

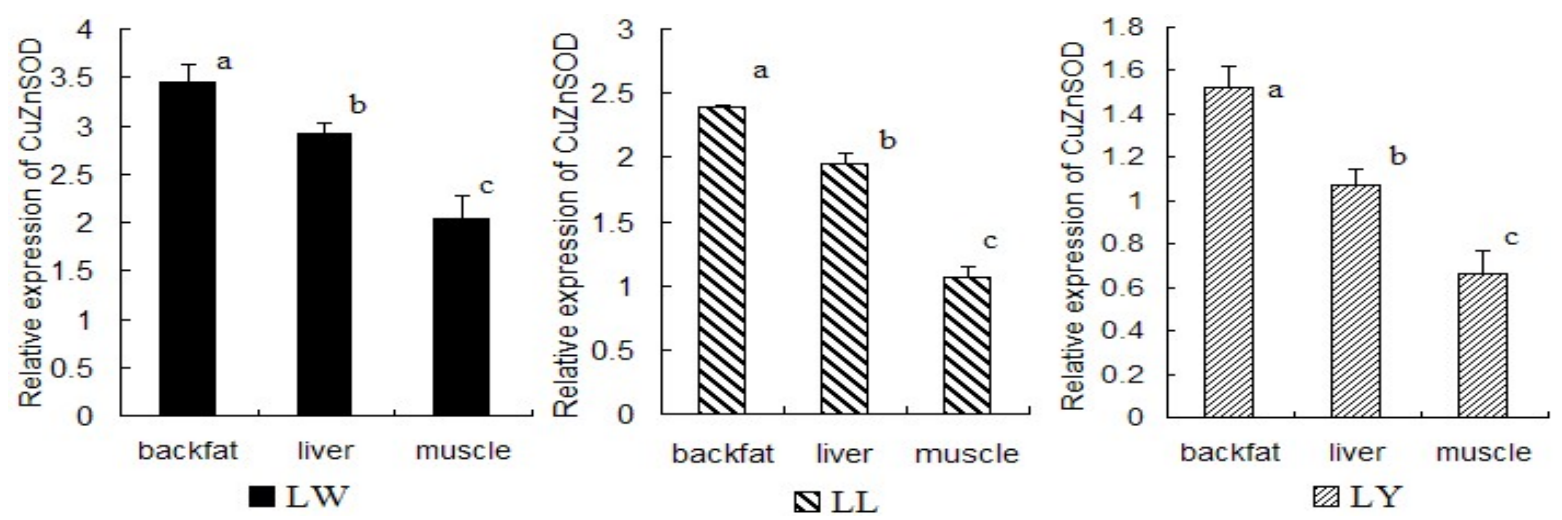

Figure 1 Differences of CuZnSOD mRNA expression in various tissues. Letters denote the difference of expression level with significantly different $(\mathrm{P}<0.05)$.

LW - Laiwu Black; LL - Lulai Black; LY - Large Yorkshire.

Table 2 Superoxide dismutase (SOD) activity and malondialdehyde (MDA) level in muscle

\begin{tabular}{|c|c|c|c|c|c|c|c|c|}
\hline \multirow{2}{*}{ Breed } & \multicolumn{4}{|c|}{ SOD activity (U/mg protein) } & \multicolumn{4}{|c|}{ MDA level (nmol/mg protein) } \\
\hline & $\mathrm{SOD}_{1 \mathrm{~d}}$ & $\mathrm{SOD}_{2 \mathrm{~d}}$ & $\mathrm{SOD}_{3 \mathrm{~d}}$ & $\mathrm{SOD}_{5 \mathrm{~d}}$ & $\mathrm{MDA}_{1 \mathrm{~d}}$ & $\mathrm{MDA}_{2 \mathrm{~d}}$ & $\mathrm{MDA}_{3 \mathrm{~d}}$ & $\mathrm{MDA}_{5 \mathrm{~d}}$ \\
\hline LW & $17.34 \pm 0.71$ & $13.86 \pm 0.56$ & $10.95 \pm 0.46$ & $6.87 \pm 0.27$ & $0.26 \pm 0.01$ & $0.32 \pm 0.02$ & $0.50 \pm 0.02$ & $0.92 \pm 0.03$ \\
\hline LL & $15.93 \pm 0.74$ & $12.12 \pm 0.58$ & $8.59 \pm 0.48$ & $5.42 \pm 0.29$ & $0.26 \pm 0.01$ & $0.41 \pm 0.02$ & $0.58 \pm 0.02$ & $0.97 \pm 0.02$ \\
\hline LY & $13.56 \pm 0.74$ & $10.27 \pm 0.59$ & $7.70 \pm 0.47$ & $4.51 \pm 0.28$ & $0.34 \pm 0.01$ & $0.45 \pm 0.01$ & $0.64 \pm 0.01$ & $1.03 \pm 0.01$ \\
\hline
\end{tabular}

$\mathrm{SOD}_{1 \mathrm{~d}}, \mathrm{SOD}_{2 \mathrm{~d}}, \mathrm{SOD}_{3 \mathrm{~d}}, \mathrm{SOD}_{5 \mathrm{~d}}=\mathrm{SOD}$ activity at $1,2,3$, and 5 days, respectively.

$\mathrm{MDA}_{1 \mathrm{~d}}, \mathrm{MDA}_{2 \mathrm{~d}}, \mathrm{MDA}_{3 \mathrm{~d}}, \mathrm{MDA}_{5 \mathrm{~d}}=$ MDA level at 1, 2, 3 and 5 days, respectively.

LW - Laiwu Black; LL - Lulai Black; LY - Large Yorkshire.

Table 3 Meat quality properties of the different pig breeds

\begin{tabular}{lcccccc}
\hline Breed & MC & DL (\%) & CL (\%) & SF (N) & IMF (\%) & MS \\
\hline LW & $2.83 \pm 0.44$ & $0.69 \pm 0.73$ & $16.83 \pm 4.58$ & $37.55 \pm 4.76$ & $12.78 \pm 3.55$ & $4.83 \pm 0.25$ \\
LL & $2.50 \pm 0.50$ & $1.81 \pm 1.38$ & $26.85 \pm 2.56$ & $38.95 \pm 4.97$ & $7.27 \pm 4.40$ & $4.05 \pm 1.08$ \\
LY & $2.18 \pm 0.64$ & $2.87 \pm 1.36$ & $29.57 \pm 3.73$ & $37.49 \pm 4.36$ & $1.15 \pm 0.23$ & $1.68 \pm 0.34$
\end{tabular}

MC - meat colour score (1 - 6); DL - drip loss; CL - cooking loss; SF - shear force; IMF - intramuscular fat; MS marbling score $(1-5)$.

LW - Laiwu Black; LL - Lulai Black; LY - Large Yorkshire.

In all three groups the mRNA expression level of the CuZnSOD gene was positively correlated $(\mathrm{P}<0.05)$ with SOD activity from day 1 to 5 , while that of CuZnSOD was highly positively correlated (P $<0.01)$ with $\mathrm{SOD}_{2 \mathrm{~d}}$ in LW. The CuZnSOD mRNA expression level was negatively correlated $(\mathrm{P}<0.05)$ with MDA level from day 1 to 5, while in LW there was no obvious relationship between gene expression and $\mathrm{MDA}_{1 \mathrm{~d}}(\mathrm{P}>0.05)$. The mRNA expression level of CuZnSOD was highly negatively correlated $(\mathrm{P}<0.01)$ with $\mathrm{MDA}_{3 \mathrm{~d}}$ and $\mathrm{MDA}_{5 \mathrm{~d}}$ in $\mathrm{LW}$, and negatively correlated $(\mathrm{P}<0.01)$ with $\mathrm{MDA}_{5 \mathrm{~d}}$ in $\mathrm{LL}$, and negatively correlated $(\mathrm{P}<0.01)$ with $\mathrm{MDA}_{3 \mathrm{~d}}$ in LY.

It is sufficient to indicate that there was a correlation between CuZnSOD gene expression and meat quality $(\mathrm{P}<0.05)$. The abundance of CuZnSOD mRNA expression in muscles was negatively correlated with drip loss, cooking loss, marbling score, shear force, IMF $(\mathrm{P}<0.05)$, and positively correlated with meat colour $(\mathrm{P}<0.05)$. 
Table 4 Correlation analysis between CuZnSOD mRNA expression and superoxide dismutase (SOD) level in muscle during storage over a period of five days

\begin{tabular}{lcrrrrrrr}
\hline \multirow{2}{*}{ Gene expression } & \multicolumn{2}{c}{$\mathrm{SOD}_{1 \mathrm{~d}}$} & \multicolumn{2}{c}{$\mathrm{SOD}_{2 \mathrm{~d}}$} & \multicolumn{2}{c}{$\mathrm{SOD}_{3 \mathrm{~d}}$} & \multicolumn{2}{c}{$\mathrm{SOD}_{5 \mathrm{~d}}$} \\
\cline { 2 - 10 } & $\mathrm{r}$ & \multicolumn{1}{c}{$\mathrm{P}$} & $\mathrm{r}$ & $\mathrm{P}$ & $\mathrm{r}$ & $\mathrm{P}$ & $\mathrm{r}$ & $\mathrm{P}$ \\
\hline \multirow{2}{*}{ Laiwu Black } & $0.628^{*}$ & 0.029 & $0.905^{* *}$ & $<0.001$ & $0.630^{*}$ & 0.028 & $0.846^{*}$ & 0.001 \\
Lulai Black & $0.608^{*}$ & 0.036 & $0.638^{*}$ & 0.026 & $0.612^{*}$ & 0.034 & $0.810^{*}$ & 0.001 \\
Large Yorkshire & $0.687^{*}$ & 0.014 & $0.663^{*}$ & 0.019 & $0.685^{*}$ & 0.014 & $0.582^{*}$ & 0.047 \\
\hline
\end{tabular}

* - Significant $(\mathrm{P}<0.05)$; ** - Significant $(\mathrm{P}<0.01)$.

$\mathrm{SOD}_{1 \mathrm{~d}}$ to $\mathrm{SOD}_{5 \mathrm{~d}}-$ referring to days 1 to 5 .

Table 5 Correlation analysis between CuZnSOD mRNA expression and malondialdehyde (MDA) level in muscle during storage over a period of five days

\begin{tabular}{lccccccccc}
\hline Gene & \multicolumn{2}{c}{$\mathrm{MDA}_{1 \mathrm{~d}}$} & \multicolumn{2}{c}{$\mathrm{MDA}_{2 \mathrm{~d}}$} & \multicolumn{2}{c}{$\mathrm{MDA}_{3 \mathrm{~d}}$} & \multicolumn{2}{c}{$\mathrm{MDA}_{5 \mathrm{~d}}$} \\
\cline { 2 - 9 } & $\mathrm{r}$ & $\mathrm{P}$ & $\mathrm{r}$ & $\mathrm{P}$ & $\mathrm{r}$ & $\mathrm{P}$ & $\mathrm{r}$ & $\mathrm{P}$ \\
\hline Laiwu Black & -0.523 & 0.081 & $-0.746^{*}$ & 0.005 & $-0.897^{* *}$ & $<0.001$ & $-0.923^{* *}$ & $<0.001$ \\
Lulai Black & $-0.732^{*}$ & 0.007 & $-0.581^{*}$ & 0.048 & $-0.619^{*}$ & 0.032 & $-0.883^{* *}$ & $<0.001$ \\
Large Yorkshire & $-0.815^{*}$ & 0.001 & $-0.625^{*}$ & 0.029 & $-0.878^{* *}$ & $<0.001$ & $-0.720^{*}$ & 0.010 \\
\hline
\end{tabular}

* - Significant $(\mathrm{P}<0.05)$; ** - Significant $(\mathrm{P}<0.01)$.

$\mathrm{MDA}_{1 \mathrm{~d}}$ to $\mathrm{MDA}_{5 \mathrm{~d}}-$ referring to days 1 to 5 .

Table 6 Correlation analysis between CuZnSOD mRNA expression and meat quality

\begin{tabular}{lllllll}
\hline \multirow{2}{*}{ Trait } & \multicolumn{2}{c}{ Laiwu Black } & \multicolumn{2}{c}{ Lulai Black } & \multicolumn{2}{c}{ Large Yorkshire } \\
\cline { 2 - 7 } & \multicolumn{1}{c}{$\mathrm{r}$} & $\mathrm{P}$ & $\mathrm{r}$ & $\mathrm{P}$ & $\mathrm{r}$ & $\mathrm{P}$ \\
\hline MC & $0.712^{* *}$ & 0.001 & $0.765^{* *}$ & 0.004 & $0.857^{* *}$ & $<0.001$ \\
DL & $-0.616^{*}$ & 0.033 & $-0.870^{* *}$ & $<0.001$ & $-0.938^{* *}$ & $<0.001$ \\
CL & $-0.581^{*}$ & 0.047 & $-0.726^{* *}$ & 0.008 & $-0.918^{* *}$ & $<0.001$ \\
SF & $-0.943^{* *}$ & $<0.001$ & $-0.891^{* *}$ & $<0.001$ & $-0.902^{* *}$ & $<0.001$ \\
IMF & -0.470 & 0.130 & $-0.582^{*}$ & 0.047 & $-0.637^{*}$ & 0.026 \\
MS & $-0.593^{*}$ & 0.042 & $-0.678^{*}$ & 0.016 & $-0.930^{* *}$ & $<0.001$
\end{tabular}

* - Significant $(\mathrm{P}<0.05)$; ** - Significant $(\mathrm{P}<0.01)$.

MC - meat colour score; DL - drip loss; CL - cooking loss; SF - shear force; IMF - intramuscular fat; MS - marbling score.

\section{Discussion}

CuZnSOD mRNA level is significantly different between tissues, with that in backfat $>$ liver $>$ muscle in all three breeds. A dissimilar conclusion was reported by Xu et al. (2007) for Duroc $\times$ Landrace $\times$ Yorkshire boars. They reported that CuZnSOD mRNA levels in muscle were the highest of the tested tissues. From this investigation we concluded that there was a breed $\times$ tissue interaction, and CuZnSOD mRNA expression is influenced not only by tissue, but also by breed. The pattern of CuZnSOD mRNA expression varies in different tissues. It is well known that ROS can easily attack lipids to yield lipid hydroperoxides, and backfat tissue is potentially predisposed to lipid peroxidation due to its high concentration of polyunsaturated fatty acids, which are susceptible to oxidation. Consequently, results show a higher $\mathrm{CuZnSOD}$ expression in fat than in muscle.

CuZnSOD mRNA level was shown as LW $>$ LL $>$ LY. The reason for such discrepancies is attributed to the high variation of CuZnSOD activity among the breeds. It demonstrates that a simple relationship does always exist between the mRNA levels and the activity of antioxidases in particular tissues. CuZnSOD is the 
antioxidant enzyme to increase in both activity and gene mRNA expression from the LY to the LW muscle. These results suggest that post-transcriptional control mechanisms must play a role in the regulation of CuZnSOD expression. The transcriptional activation of antioxidant enzymes has been related to cisacting elements, detected in the promoter region of those genes. They regulate either or both constitutive and inducible gene expression (Dhakshinamoorthy et al., 2000).

Our study identified that there is a relationship between CuZnSOD gene expression and MDA content, and that CuZnSOD gene expression is negatively correlated with MDA in the three breeds. Meanwhile, CuZnSOD gene expression positively correlate with SOD in the three breeds. This implies that the higher the level of CuZnSOD mRNA expression, the better the muscle's anti-oxidative capacity; which is in agreement with other reports (Yuan et al., 1996). On one hand, PUFAs peroxidation gives rise to a number of secondary products. MDA is the principal and most studied product of PUFAs peroxidation. Ohrvall et al. (1994) reported that the plasma concentration of MDA is negatively correlated with lipid concentration. Therefore, the measurement of MDA is important for the assessment of oxidative stress as MDA has been used as a biomarker of lipid oxidation for more than 30 years (DelRio et al., 2005). On the other hand, the activity of antioxidant enzyme represents anti-oxidative capacity in an organism; the more the CuZnSOD gene expression, the higher the SOD activity and the lower the MDA content.

In the present research, CuZnSOD mRNA expression was significantly correlated with meat quality in muscle, suggesting that the higher the level of CuZnSOD mRNA expression, the better the meat colour would be, and the lower the drip loss, cooking loss, marbling score, shear force and IMF would be. It is clear that post mortem events that are key factors in influencing meat quality such as meat processing, storage, transport and sale, produce ROS as part of normal metabolic activities, and determine the degree of drip loss, meat colour, shear force (Fernandez et al., 1997; Lonergan et al., 2005; Teye et al., 2006). The lipolytic and proteolytic rates of post mortem meat are controlled by the antioxidative ability of meat (Duval et al., 2003), and SOD can protect pork from oxidation, ameliorate meat quality and lengthen shelf life of food (Yu et al., 2009). The value of SOD can be used as an indicator for evaluating meat quality (Rowe et al., 2004); the higher the level of CuZnSOD mRNA expression, the better the meat quality and the longer the shelf life of the meat.

\section{Conclusions}

We have demonstrated clear differences in the expression of the CuZnSOD gene in fatty (LW) and lean breeds (LY) of pigs, and the regulatory mechanism of CuZnSOD gene expression occurring in different tissues of pigs has been defined. In addition, the relationship between CuZnSOD mRNA expression and meat quality are shown, but tissue-specific functions of CuZnSOD mRNA expression are poorly defined and need further investigation. Finally, these findings strongly suggest that the CuZnSOD mRNA expression in pigs is not only different among the muscle, backfat and liver, but also between breeds. CuZnSOD mRNA expression was correlated with meat quality, suggesting that CuZnSOD mRNA expression could have an influence on meat quality by affecting SOD activity and anti-oxidant ability of muscle. The results from association analyses have suggested that the porcine CuZnSOD gene is a candidate gene for anti-oxidant ability of muscle, which may be useful as a genetic marker in pig breeding.

\section{Acknowledgments}

This work was supported by the National Programme for High Technology Research and Development (No. 2008AA101008), the National Project for Breeding of Transgenic Pig (No. 2008ZX08006-002), Shandong Province Agricultural Animal Breeding Project (No. 2007LZ013), Shandong Province Natural Science Foundation (No. Y2008D32).

\section{References}

Covarrubias, L., García, D.H., Schnabel, D., Vidal, E.S. \& Obregon, S.C., 2008. Function of reactive oxygen species during animal development: Passive or active. Dev. Biol. 320, 1-11.

Day, B.J., 2009. Catalase and glutathione peroxidase mimics. Biochem. Pharmacol. 77, 285-296.

DelRio, D.A., Stewart, J. \& Pellegrini, N., 2005. A review of recent studies on malondialdehyde as toxic molecule and biological marker of oxidative stress. Nutr. Metab. Cardiovas. 15, 316-328. 
Dhakshinamoorthy, S., Long, D.J. \& Jaiswal, A.K., 2000. Antioxidant regulation of genes encoding enzymes that detoxify xenobiotica and carcinogens. Curr. Top. Cell. Regul. 36, 201-216.

Duval, C., Cantero, A.V., Auge, N., Mabile, L., Thiers, J.C., Salavayre, A.V. \& Salvayre, R., 2003. Proliferation and wound healing of vascular cells trigger the generation of extracellular reactive oxygen species and LDL oxidation. Free Radical Bio. Med. 35, 1589-1598.

Erkens, T., Van, P.M., Vandesompele, J., Goossens, K., Van, Z.A. \& Peelman, L.J., 2006. Development of a new set of reference genes for normalization of real-time RT-PCR data of porcine backfat and longissimus dorsi muscle, and evaluation with PPARGC/A. BMC Biotechnology 6, 41-48.

Fernandez, J., Perez-Alvarez, J.A. \& Fernandez-Lopez, J.A., 1997. Thiobarbituric acid test for monitoring lipid oxidation in meat. Food Chem. 59, 345-353.

Frank, L. \& Sosenko, I., 1987. Prenatal development of lung antioxidant enzymes in four species. J. Pediatr. 110, 106-110.

Halliwell, B., 1991. Reactive oxygen species in living systems: source, biochemistry, and role in human disease. Am. J. Med. 91, 14-22.

Honikel, K.O., 1998. Reference methods for the assessment of physical characteristics of meat. Meat Sci. 49, 447-457.

Hu, H.M., Wang, J.Y., Zhu, R.S., Guo, J.F. \& Wu, Y., 2008. Effect of myosin heavy chain composition of muscles on meat quality in Laiwu pigs and Duroc. Science in China Series C: Life Sciences 51, 127-132.

Livak, K.J. \& Schmittgen, T.D., 2001. Analysis of relative gene expression data using real-time quantitative PCR and the 2(-Delta Delta C (T)) method. Methods 25, 402-408.

Lonergan, E.H. \& Lonergan, S.M., 2005. Mechanisms of water-holding capacity of meat: The role of postmortem biochemical and structural changes. Meat Sci. 71, 194-204.

Lonergan, E.H., Baas, T.J., Malek, M., Dekkers, J.C., Prusa, K. \& Rothschild, M.F., 2002. Correlations among selected pork quality traits. J. Anim. Sci. 80, 617-627.

Lu, P., Li, D.F., Yin, J.D., Zhang, L.Y. \& Wang, Z.Y., 2008. Flavour differences of cooked longissimus muscle from Chinese indigenous pig breeds and hybrid pig breed (Duroc $\times$ Landrace $\times$ Large White). Food Chem. 107, 1529-1537.

Malathi, B., Aryamani, B., Robert, A.T., Leo, S.L. \& James, D.T., 2008. Evaluation and validation of housekeeping genes in response to ionizing radiation and chemical exposure for normalizing RNA expression in real-time PCR. Mutat. Res. 649, 126-134.

Mateos, R., Lecumberri, E., Ramos, S., Goya, L. \& Bravo, L., 2005. Determination of malondialdehyde (MDA) by high-performance liquid chromatography in serum and liver as a biomarker for oxidative stress, Application to a rat model for hypercholesterolemia and evaluation of the effect of diets rich in phenolic antioxidants from fruits. J. Chromatogr. B. 827, 76-82.

Miao, L. \& Clair, D.K., 2009. Regulation of superoxide dismutase genes: Implications in disease. Free Radical Bio. Med. 47, 344-356.

Michiels, C., Raes, M., Toussaint, O. \& Remacle, J., 1994. Importance of SE-glutathione peroxidase, catalase, and CuZnSOD for cell survival against oxidative stress. Free Radical Bio. Med. 17, 235-248.

Noor, R., Mittal, S. \& Iqbal, J., 2002. Superoxide dismutase-applications and relevance to human diseases. Med. Sci. Moint. 8, 210-215.

Ohrvall, M., Tengblad, S., Ekstrand, B., Siegbahn, A. \& Vessby, B., 1994. Malondialdehyde concentration in plasma is inversely correlated to the proportion of linoleic acid in serum lipoprotein lipids. Atherosclerosis 108, 103-110.

Robert, D.B., Dan, W.H., Robert, A.C. \& Brian, J.C., 2005. GAPDH as a housekeeping gene: Analysis of GAPDH mRNA expression in a panel of 72 human tissues. Physiol. Genomics 21, 389-395.

Rowe, L.J., Maddock, K.R., Lonergan, S.M. \& Huff-Lonergan, E., 2004. Oxidative environments decrease tenderization of beef steaks through inactivation of $\mu$-calpain. J. Anim. Sci. 82, 3254-3266.

Ryan, S.M., Unruh, J.A., Adhikari, K., Hunt, M.C., Kaster, C.S. \& Matthews, J.O., 2010. Prediction of Japanese color score. Meat Sci. 84, 165-171.

SAS, 1999. SAS/STAT User's guide, Version 8. Cary, N.C., SAS Institute Inc. 
Takada, S., Inoue, E., Tano, K., Yoshii, H., Abe, T., Yoshimura, A., Akita, M., Tada, S., Watanabe, M., Seki, M. \& Enomoto, T., 2009. Generation and characterization of cells that can be conditionally depleted of mitochondrial SOD2. Biochem. Bioph. Res. Co. 379, 233-238.

Teye, G.A., Sheard, P.R., Whittington, F.M., Nute, G.R., Stewart, A. \& Wood, J.D., 2006. Influence of dietary oils and protein level on pork quality. 1. Effects on muscle fatty acid composition, carcass, meat and eating quality. Meat Sci. 73, 157-165.

Xu, C.L., Wang, Y.Z., Guo, J., Liu, J.X. \& Feng, J., 2007. Comparison of age-related differences in expression of antioxidant enzyme mRNA and activity in various tissues of pigs. Comp. Biochem. Physiol. B. Biochem. Mol. Biol. 147, 445-451.

Yu, H.J., Ge, Y., Wang, Y., Lin, C.T., Li, J., Liu, X.M., Zang, T.Z., Xu, J.Y., Liu, J.Q., Luo, G.M. \& Shen, J.C., 2007. A fused selenium-containing protein with both GPx and SOD activities. Biochem. Bioph. Res. Co. 358, 873-878.

Yu, J.M., Tang, S., Bao, E.D., Zhang, M., Hao, Q.Q. \& Yue, Z.H., 2009. The effect of transportation on the expression of heat shock proteins and meat quality of M. longissimus dorsi in pigs. Meat Sci. 83, 474-478.

Yuan, H.T., Bingle, C.D. \& Kelly, F.J., 1996. Different patterns of antioxidant enzyme mRNA expression in guinea pig lung and liver during development. Biochim. Biophys. 1305, 163-171.

Yuan, J.S., Wang, D. \& Sewart, C.N., 2008. Statistical methods for efficiency adjusted real-time PCR quantification. Biotechnol. J. 3, 112-123. 